\title{
Reliability test and analysis for a steel truss of coal
}

\section{conveying belt corridor}

\author{
Liu Haitao ${ }^{1, a}$, Wei Kelun ${ }^{2, b}$, Zhang Fengjian ${ }^{1, a}$, Sun Qing ${ }^{3, d^{*}}$ \\ ${ }^{1}$ Henan Electric Power Survey and Design Institute, Zhengzhou 450007, China \\ ${ }^{2}$ Henan University Of Urban Construction,School of civil and transportation Engineering, Henan \\ pingdingshan 467036, China \\ ${ }^{3}$ Department of Civil Engineering, Xi'an Jiaotong University, Xi'an, 710049, China \\ $\mathrm{d}^{\star}$ sunq@mail.xjtu.edu.cn
}

Keywords : Steel truss; Test

\begin{abstract}
A belt corridor of Pingdingshan tianan coal company was built in the $1980 \mathrm{~s}$, after 30 years of use, lower chord and lower chord node of steel truss structure rust serious, bearing capacity of bar and node plate has not meet the design requirements, that being serious security hidden danger to producing activity. To assess the reliability of steel truss, according to the relevant national standard for test and calculation analysis, determine the level of reliability by test, and gives the conclusion and suggestion.
\end{abstract}

\section{Introduction}

A coal conveying belt corridor of Pingdingshan tianan coal company was built in the 1980s, this coal conveying belt corridor is large span, perennial work under dynamic load, bearing structure is steel truss system ${ }^{[1]}$. But because of the bad use conditions of coal preparation plant, the corrosive medium is more, plus the improper maintenance during use, lower chord and lower chord node of steel truss structure rust serious, bearing capacity of bar and node plate has not meet the design requirements, that being serious security hidden danger to producing activity ${ }^{[2,3]}$. To assess the reliability of steel truss, according to the relevant national standard for test and calculation analysis, determine the level of reliability by test, and gives the conclusion and suggestion.

\section{Engineering situation}

A coal conveying belt corridor of Pingdingshan tianan coal company, is located in the middle of pingdingshan mining area, structure form is the level of single span simply supported steel truss structure, with continuous belt transmission machine, length of 31.2 meters. Both ends of the belt corridor respectively is supported by concrete frame transfer station and concrete column bracket, belt corridor across coal railway of the first mine coal preparation plant. In the middle of belt corridor is coal conveying belt, two side of belt corridor is the pavement, belt corridor appearance and internal structure are shown in figure 1 and figure 2. Steel truss uses double angle and bar, is a simply-supported structure, one end is a rolling bearing, the other end is fixed 
support. The belt corridor roof adopts the wooden board with light color steel plate, Wall adopts $20 \mathrm{~mm}$ thick wood panels and glass steel window with color steel plate, floor and roof plate adopts 200 (now C18) precast reinforced concrete tank plate. Using common carbon steel structure material A3 steel (now for Q235 steel), allowable stress is $1700 \mathrm{~kg} / \mathrm{cm} 2$, electrode uses T420 type electrode, steel structure with red lead render, and adopts grey ink for corrosion protection.

The project was built in the $1980 \mathrm{~s}$, since put into use has been more than thirty years history, due to the effect of mining area work climate and humid conditions, long-term adverse work environment, corrosion situation is increasingly serious, the structure safety is reduced. In order to ensure the safety of the whole production system of coal preparation plant, we test structure safety and reinforce steel truss of coal conveying belt corridor.

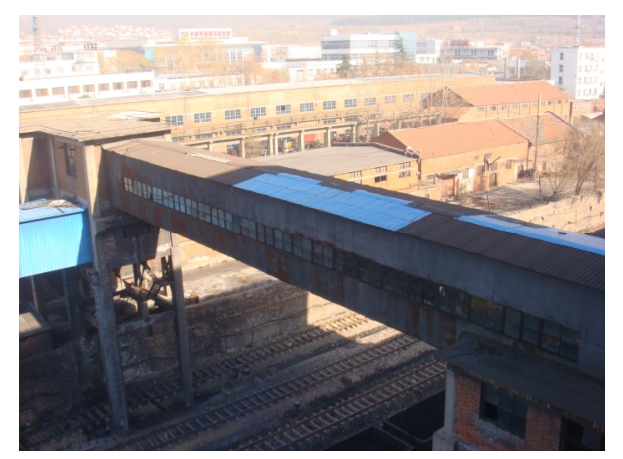

Fig.1 The external structure of 901 belt corridor

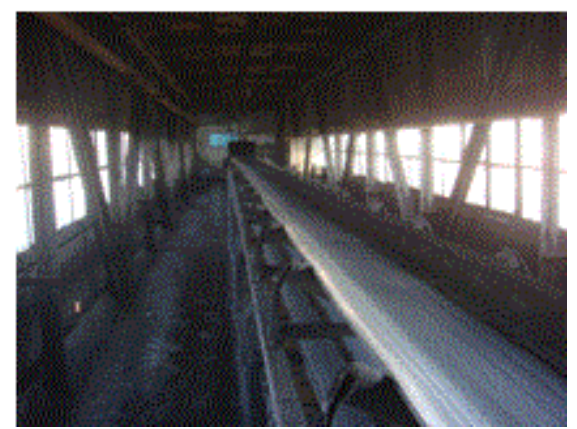

Fig. 2 The internal structure of 901 belt corridor

\section{Steel truss bearing capacity calculation and rating}

Coal conveying belt corridor of the first mine is made of two same size steel truss, top chord adopts $2\llcorner 125 \times 14$ double angle bar, lower chord adopts $2\llcorner 110 \times 8$ double angle bar. Two steel truss structure is connected by level of support and beam, steel truss structure is parallel chord truss with herringbone diagonal and vertical bar, one end fixed hinge, the other end of the roll hinge, it can be simplified as a plane truss to calculate bearing capacity, calculation diagram and node number are shown in figure 3 .

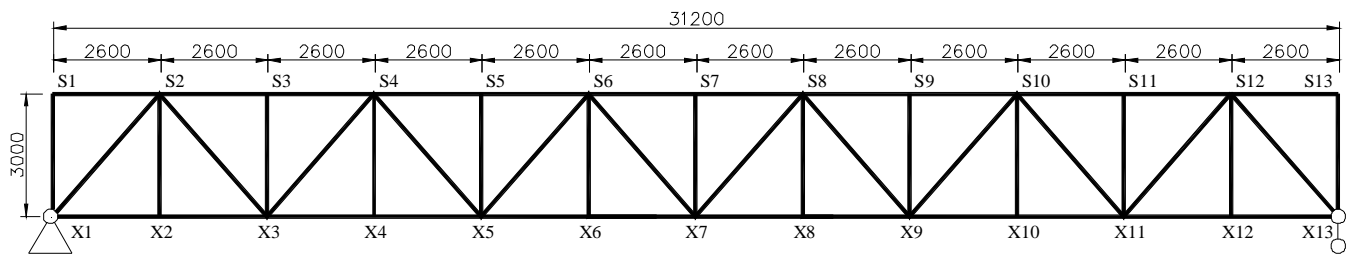

Fig.3 The calculating diagram of steel truss 
Through field test, all the year round coal slurry accumulation on the floor of the belt corridor, due to containing corrosive medium in the coal slurry, bottom chord and bottom chord node of truss and steel bearing caused serious corrosion. Through field test ${ }^{[4]}$, part of the bottom chord and bottom chord node has been corroded seriously, residual thickness is about $80 \%$ of the thickness of original component, that is a danger; fixed end steel bearings, remaining thickness of stiffening rib is $5 \mathrm{~mm}$, is only about $30 \%$ of the thickness of the original design, can not meet the requirements of steel structure construction ${ }^{[5]}$.

According to industrial building reliability appraisal standard, steel structure bearing capacity rating should be based on the force $\mathrm{R}$ and effect $\mathrm{S}$ of structural components and structure importance coefficient $\gamma_{0}$. Should be considered in determination of the force $\mathrm{R}$ of structural components, the actual material properties and structure, and structure damage, corrosion, large deformation, and the influence of deviation.

Table 1 Component bearing capacity rating

\begin{tabular}{|c|c|c|c|c|}
\hline \multirow{2}{*}{ Component types } & \multicolumn{4}{|c|}{$\mathrm{R} / \gamma_{0} \mathrm{~S}$} \\
\cline { 2 - 5 } & $\mathrm{a}$ & $\mathrm{b}$ & $\mathrm{c}$ & $\mathrm{d}$ \\
\hline Important component & $\geq 1.00$ & $<1.00, \geq 0.95$ & $<0.95, \geq 0.90$ & $<0.90$ \\
\hline Secondary components & $\geq 1.00$ & $<1.00, \geq 0.92$ & $<0.92, \geq 0.87$ & $<0.87$ \\
\hline
\end{tabular}

According to table 1 , in the of the truss bearing capacity calculation, we calculate bar capacity and bearing capacity after corrosion, calculation results are shown in table 2 and table 3.

Table 2 Bearing capacity calculation of truss on the east side of 901 belt corridor

\begin{tabular}{|c|c|c|c|c|c|}
\hline Member bar & $\begin{array}{c}\text { The number of } \\
\text { member bar } \\
\text { of member bar } \\
\text { for level A }\end{array}$ & $\begin{array}{c}\text { The number } \\
\text { of for level } \\
\text { B }\end{array}$ & $\begin{array}{c}\text { The number } \\
\text { member bar for } \\
\text { level C }\end{array}$ & $\begin{array}{c}\text { The number of } \\
\text { member bar for } \\
\text { level D }\end{array}$ \\
\hline Upper chord & 12 & 12 & 0 & $\mathbf{0}$ & 0 \\
\hline Lower chord & 12 & 10 & 2 & $\mathbf{0}$ & 0 \\
\hline Web member & 25 & 21 & 3 & $\mathbf{1}$ & 0 \\
\hline
\end{tabular}

Table 3 Bearing capacity calculation of truss on the west side of 901 belt corridor

\begin{tabular}{|c|c|c|c|c|c|}
\hline Member bar & $\begin{array}{c}\text { The number of } \\
\text { member bar } \\
\text { of member bar } \\
\text { for level A }\end{array}$ & $\begin{array}{c}\text { The number } \\
\text { of member } \\
\text { bar for level } \\
\text { B }\end{array}$ & $\begin{array}{c}\text { The number } \\
\text { member bar for } \\
\text { level C }\end{array}$ & $\begin{array}{c}\text { The number of } \\
\text { member bar for } \\
\text { level D }\end{array}$ \\
\hline Upper chord & 12 & 12 & 0 & $\mathbf{0}$ & 0 \\
\hline Lower chord & 12 & 10 & 1 & $\mathbf{1}$ & 0 \\
\hline Web member & 25 & 20 & 4 & $\mathbf{1}$ & 0 \\
\hline
\end{tabular}


Table 4 Bearing capacity calculation of truss for 901 belt corridor

\begin{tabular}{|c|c|c|c|c|c|}
\hline Bearing & $\begin{array}{c}\text { Actual } \\
\text { bearing } \\
\text { capacity } \\
\mathrm{R}(\mathrm{kN})\end{array}$ & $\begin{array}{c}\text { Calculation } \\
\text { bearing capacity } \\
\mathrm{S}(\mathrm{kN})\end{array}$ & $\mathrm{R} / \gamma_{0} \mathrm{~S}$ & $\begin{array}{c}\text { Bearing } \\
\text { capacity rating }\end{array}$ & Note \\
\hline Bearing on the southeast & 97.36 & 114.54 & 0.85 & level D & $\begin{array}{c}\text { Serious } \\
\text { corrosion }\end{array}$ \\
\hline Bearing on the southwest & 99.65 & 114.54 & 0.87 & level D & Serious \\
\hline Bearing on the northeast & 112.25 & 114.54 & 0.98 & level B & level B \\
\hline Bearing on the northwest & 111.11 & 114.54 & 0.97 & \\
\hline
\end{tabular}

According to table 2 and table 3 and table 4, in the belt corridor part of bar's bearing capacity is insufficient, and serious lack of support's bearing capacity, can not meet the original design requirements, through the comprehensive rating, reliability level is level 4.

According to the results of field test and bearing capacity calculation, fixed end steel bearings is severe corrosion, bearing capacity is obviously insufficient, has been very dangerous, recommended that use reinforced concrete joint reinforcement method after rust cleaning; for lack of the bar'sbearing capacity can use increasing section method, corrosion serious node plate can be reinforced by using increasing section method.

\section{Conclusion}

Based on the test of rusting steel truss, conclusion as follows :

1) According to the belt corridor corrosion level, bar bearing capacity assessment level and support's bearing capacity rating, belt corridor comprehensive reliability level is level 4.

2) The coal conveying belt corridor's node and lower chord anti-corrosive paint has been basically finished off, lost anti-corrosion features, suggest that implement the preservative treatment as soon as possible, to ensure that the steel structural member and node anti-corrosion ability.

3) Due to severe corrosion of bars and nodes, bearing capacity is insufficient or serious decline, suggest to reinforce bar and node which's bearing capacity is insufficient, guarantee the bearing capacity of steel structure system.

\section{Reference}

[1] Tao Bai. Wind vibration response analysis of long-span steel structure pier [D]. Shanxi : Xi an University of Architecture and Technology,2013

[2] Shi-Mei Huang. Bearing capacity analysis for steel structure trestle of old coal conveying corridor. Henan: Zhengzhou University, 2009. 
[3] Bing Guo. Inspection appraisal and reinforcement transformation for steel structure [M]. Beijing: China Architecture and Building Press, 2006.

[4] GB/T50621-2010 Technical standard for in-site testing of steel structure [S]. Beijing: China Architecture and Building Press, 2011.

[5] GB50017-2003 Code for design of steel structure [S]. Beijing: China planning Press,2003.

[6] GB50144-2008 Reliability appraisal standard of industrial building [S]. Beijing: China planning Press, 2009. 